\title{
Impact of Environmental Exposure on the Service Life of Façade Claddings-A Statistical Analysis
}

\author{
Joana Barrelas ${ }^{1, *(\mathbb{D}}$, Ilídio S. Dias ${ }^{1} \mathbb{D}$, Ana Silva ${ }^{1}\left(\mathbb{D}\right.$, Jorge de Brito ${ }^{1,2} \mathbb{D}$, Inês Flores-Colen ${ }^{1,2} \mathbf{D}^{\mathbb{D}}$ \\ and António Tadeu ${ }^{3,4}$ (i)
}

1 CERIS, Instituto Superior Técnico (IST), University of Lisbon, Av. Rovisco Pais, 1049-001 Lisbon, Portugal; ilidio.dias@tecnico.ulisboa.pt (I.S.D.); ana.ferreira.silva@tecnico.ulisboa.pt (A.S.); jb@civil.ist.utl.pt (J.d.B.); ines.flores.colen@tecnico.ulisboa.pt (I.F.-C.)

2 Department of Civil Engineering, Architecture and Georesources, IST, University of Lisbon, Av. Rovisco Pais, 1049-001 Lisbon, Portugal

3 Department of Civil Engineering, University of Coimbra, ADAI—LAETA, Pólo II, Rua Luís Reis Santos, 3030-788 Coimbra, Portugal; tadeu@dec.uc.pt or tadeu@itecons.uc.pt

4 Itecons-Institute of Research and Technological Development in Construction, Energy, Environment and Sustainability, Rua Pedro Hispano, 3030-289 Coimbra, Portugal

* Correspondence: joana.barrelas@tecnico.ulisboa.pt

Citation: Barrelas, J.; Dias, I.S.; Silva,

A.; de Brito, J.; Flores-Colen, I.; Tadeu,

A. Impact of Environmental Exposure on the Service Life of Façade Claddings-A Statistical Analysis. Buildings 2021, 11, 615. https:// doi.org/10.3390/buildings11120615

Academic Editor:

Emilio Bastidas-Arteaga

Received: 9 November 2021

Accepted: 28 November 2021

Published: 6 December 2021

Publisher's Note: MDPI stays neutral with regard to jurisdictional claims in published maps and institutional affiliations.

Copyright: (c) 2021 by the authors. Licensee MDPI, Basel, Switzerland. This article is an open access article distributed under the terms and conditions of the Creative Commons Attribution (CC BY) license (https:// creativecommons.org/licenses/by/ $4.0 /)$.
Abstract: Façade claddings, as the outer protection layer of the building's envelope, are directly exposed to environmental degradation agents. The façades' orientation and their distance from the sea, among other location and protection-related factors, influence their vulnerability to climate loads, in particular wind and air humidity. These loads, as well as exposure to air pollution, affect the degradation process of claddings and the durability of façades. Therefore, studying the impact of the environmental exposure conditions on the service life of different external claddings provides useful information on their performance over time, which can support (i) decision-makers in the selection of the best façade cladding solutions and (ii) further research on the impact of climate change on building components. This study covers six types of cladding: rendered façades (R), natural stone cladding (NSC), ceramic tiling system (CTS), painted surfaces (PS), external thermal insulation composite systems (ETICS), and architectural concrete façades (ACF). Three hundred façades located in Portugal are analysed according to three main groups of variables, which characterize (i) the façades, (ii) their degradation condition, and (iii) the environmental deterioration loads and context. The statistical analysis results reveal that the environmental variables affect the cladding degradation process. South-oriented façades present lower degradation conditions than façades facing north. The distance from the sea and high exposure to pollutants add to the degradation conditions, reducing the expected service life of façades. The results reveal that claddings can be organized according to two main groups: the most durable (CTS, NSC, and ACF) and the least durable (R, PS, and ETICS) systems. This study enables a comprehensive analysis of the data, useful to draw conclusions about the influence of environmental exposure conditions on the degradation and service life of façade claddings.

Keywords: façade claddings; environmental exposure; climate; degradation; service life; statistical analysis

\section{Introduction}

The environmental degradation of façade claddings is a complex phenomenon [1]. The durability of claddings depends on the following factors:

1. Action of combined climate agents, such as temperature, humidity, precipitation, and wind;

2. Location, in terms of topography, rural or urban context, altitude, and distance from the sea [2]; 
3. Immediate surrounding context, in terms of protection by vegetation or buildings.

These factors influence the microclimate on the surface of the façade, which is critical for the degradation of materials [3,4]. The microclimate further depends also on:

1. Orientation of the façade;

2. Characteristics of the building, such as height and existence of protection elements in the façade;

3. Characteristics of the cladding material.

The inherent chemical, physical, and mechanical properties of the materials, as well as the characteristics resultant from design options, are determinant to the cladding's response to climate loads and consequent vulnerability to environmental degradation [5]. Air pollution in combination with climate agents also influence the degradation of building components [6].

Façades are part of the building envelope, which is a barrier that contains all the elements separating the exterior environment from the interior, including the ground [7]. Façades are meant to protect the interior of the building from harmful climate actions [2]. The cladding, as the façade's skin [8], is particularly vulnerable to the variability of external loads over decades [2]. Cladding is the layer of the façade in direct contact with the external environment. It is the first protection layer of the building, which makes it simultaneously highly susceptible and relevant [9]. Even though the façade's cladding material is less durable than the structure of the building, it is expected to contribute to the overall durability of constructions, if properly maintained [10].

The robustness, resilience, and adaptability of the building envelope are vital, not only to protect the users, but also to prevent damage from escalating after weather events [10]. Façades are expected to meet aesthetic, comfort, safety, and durability requirements [8]. They highly influence the building's overall performance [11], and their degradation affects the quality of urban space, users' comfort and maintenance costs [1].

The study of the environmental exposure conditions' influence on the degradation of different external claddings provides useful information on their performance over time, which is relevant to unravelling the complexity inherent to façades' environmental degradation and comparing the degradation profiles between claddings. Furthermore, it supports research on the service life prediction and maintenance of façade claddings and helps decision-makers to select the best cladding system. Finally, it supports further research on the impact of climate change on façades.

\section{Background and Methodology}

This study takes previous research about the service life prediction of façade claddings as a starting point. A methodology used for predicting the service life of rendered façades was developed $[12,13]$ and the resulting model was later used as a general framework for the service life prediction of other cladding materials, including natural stone cladding (NSC), ceramic tilling system (CTS), painted surfaces (PS) [1], external thermal insulation composite system (ETICS) [14], and architectural concrete façades (ACF) [15].

The methodology is based on inspection results, which reflect the components' inservice behaviour, presenting a tendency of degradation through the commonalities between different constructions. The service life of the cladding is predicted through models, for which data on the degradation of the cladding is required. The overall condition is defined by the severity of degradation index $\left(S_{w}\right)$, corresponding to the ratio between the weighted area of observed construction defects and the total area of the cladded façade with the highest degradation level (Equation (1)) [1]:

$$
S_{w}=\frac{\sum\left(A_{n} \times k_{n} \times k_{a, n}\right)}{A \times \sum k}
$$

where $S_{w}$ is the severity of degradation (in percentage); $A_{n}$ the area affected by anomaly $n$ (in $\left.\mathrm{m}^{2}\right) ; k_{n}$ the multiplication factor for the anomaly $n ; k_{a, n}$ the weighting coefficient 
according to the relative weight of the anomaly $n ; A$ the total area of the constructive solution (in $\mathrm{m}^{2}$ ); and $k$ the multiplying factor corresponding to the highest degradation condition of the area $A$. The type of anomalies detected in the inspections can vary between claddings (e.g., cracking, stains, and detachments are the anomalies used to calculate the $S_{w}$ of R). More details on the original methodology and illustrative examples of the claddings' degradation condition can be found in $[12,13]$ and in Appendix A, respectively.

The purpose of the present study is to deepen the knowledge on the effects of environmental exposure conditions on the degradation of façade claddings. In the context of the service life prediction research, a significant amount of case studies was visually inspected to assess their degradation. In addition, information on the characteristics, location, and environmental context of the façades was collected as part of the variables to be considered in the study of each cladding type (R, NSC, CTS, PS, ETICS, and ACF). The case studies are located in different cities over Portugal, with the highest incidence in Lisbon. Over the years, a considerable amount of detailed data were collected in several databases, by material, which allowed the creation of an overall multi-cladding type sample for developing the present study.

The selection of the sample and variables, including (i) characterization of the façade, (ii) degradation condition, and (iii) environmental exposure variables applicable to the six cladding solutions, is followed by a statistical analysis of the data. First, the quantitative and qualitative variables are individually characterized. The correlation between them is then studied. Afterwards, a factorial analysis and a cluster analysis are performed, to assess the commonalities between variables and case studies, respectively. In addition, analysis of variance (ANOVA) and multiple linear regression models are developed to study the influence of the environmental variables. This methodology enables a comprehensive analysis of the data, useful to draw conclusions about the influence of environmental exposure conditions on the degradation and service life of façade claddings.

\section{Data Collection}

In the context of previous service life prediction research [1,13-15], a total of 1489 case studies were visually inspected, between 2005 and 2018. A sample with the total amount of case studies is too vast for the purpose of the present study. Therefore, the original sample is reduced to 300 façades, according to the following criteria: (i) maintaining the six cladding types (R, NSC, CTS, PS, ETICS and ACF) as part of the sample, with the same relative importance (50 case studies per material) (Figure 1), (ii) selecting façades located in Lisbon, which is the main location of the case studies, and (iii) maintaining the degradation trend given by the results of previous research on the service life prediction of façade claddings, based on $S_{w}$.

The methodology to reduce the original sample is based on the non-random selection of case studies. The objective is to create a sample representative of the existing service life prediction model's functionality [13]. The service life prediction model is based on the mean degradation curve, given by the distribution of the case studies according to $S_{w}$ (dependent variable; y-axis) and age (x-axis). The 50 case studies closest to the mean degradation curve of each material's original sample and located in Lisbon are selected to be part of the sample. The sample is defined in order to ensure the age diversity of the case studies under analysis.

\section{Characterization of the Variables That Influence the Degradation of External Claddings}

The 10 variables selected to be part of the present study (Table 1), are grouped as follows:

- Characterisation of the façade-material, age, number of floors, and cladding area;

- Characterisation of the degradation condition- $S_{w}$;

- Characterisation of the environmental conditions-orientation, distance from the sea, wind action, exposure to air humidity, and exposure to pollutants. 


\subsection{Characterization of Quantitative Variables}

The results of the descriptive univariate analysis of the quantitative variables are shown in Table 2, including the following indicators: mean $\left(\mu^{\prime}\right)$, mode, median, standard deviation $(\hat{\sigma}$, minimum, maximum, range, first quartile $-25 \%(Q 1)$, third quartile $-75 \%$ $(Q 3)$, interquartile range $(I Q R)$, coefficient of variation $(C V)$, coefficient of skewness $(\hat{\gamma})$ and kurtosis $(\hat{k})$.

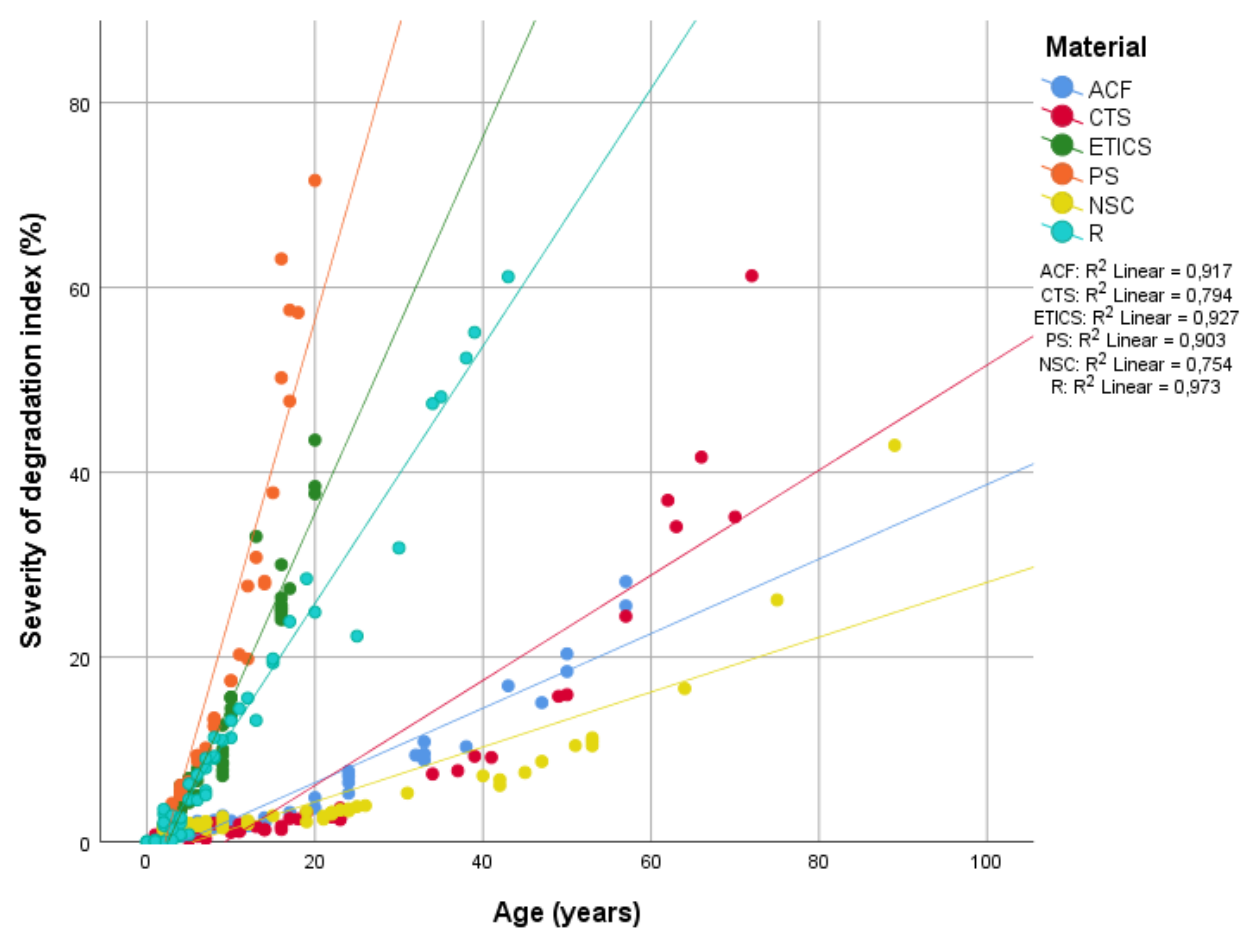

Figure 1. Scatterplot of the variables $S_{w}$ and age $(\mathrm{Ag})$ for the whole sample, with the identification of the six cladding materials.

The maximum age $(A g)$ of the façades analysed is 89 years. The degradation of the claddings is a process that evolves over time. A wide range of the ages would be useful to analyse the degradation behaviour of both recent and old façades. However, approximately $58 \%$ of the sample is characterised by ages equal to or under 10 years old. The mean is 14 years, which is quite a low value relative to the maximum age. The young age of the sample is also stressed by the mode class and median (Table 2). Generally, the façades with R, PS, and ETICS claddings, which represent half of the sample, are younger. This can be explained by (i) ETICS being a more recent cladding solution used in Portugal [16] and (ii) R, PS and ETICS having shorter service life values, which influences the age of the samples [17]. The sample is characterised by a significant dispersion and heterogeneity, considering the standard deviation $(\hat{\sigma}=15.8)$ and the coefficient of variation $(C V=107.3 \%)$. The skewness is positive $(\gamma>0)$, with a longer tail on the right side.

The analysis of the variable 'number of floors' ( $N f$ ) shows that the tallest façade inspected has 16 levels. Nevertheless, 75\% (Q3) of the case studies have up to 5 floors. The prevalence of façades of this height is stressed by the mean, mode, and median (Table 2). The visual inspection of tall façades can be challenging, due to the loss of naked-eye precision associated with the upper part of the building, caused by increased distance and distorted perspective from the street level [18-20]. The assessment of the severity of degradation is likely to be directly proportional to the precision of the visual inspection. Thus, the significant choice of medium to low-level buildings can be explained by the will to develop an accurate study. The sample is characterised by a comparatively lower dispersion and heterogeneity, considering the standard deviation $(\hat{\sigma}=2.8)$ and the 
coefficient of variation $(\mathrm{CV}=56.1 \%)$. However, the sample shows no clear asymmetry. The lowest frequencies are generally observed above 10 floors.

Table 1. Variables analysed.

\begin{tabular}{|c|c|c|c|c|c|}
\hline & Variable & Acronym & Description & Unit & Categories \\
\hline \multirow{4}{*}{ 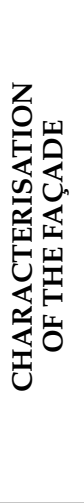 } & Material & $M a$ & $\begin{array}{l}\text { Material used as façade cladding. } \\
\text { Materials: rendering (R), natural stone cladding (NSC), } \\
\text { ceramic tilling system (CTS), painted surfaces (PS), } \\
\text { external thermal insulation composite system (ETICS), } \\
\text { and architectural concrete façades (ACF) }\end{array}$ & - & $\begin{array}{l}\text { R, NSC, CTS, PS, } \\
\text { ETICS, ACF }\end{array}$ \\
\hline & Age & $A g$ & $\begin{array}{l}\text { Period since the date of the most recent improvement } \\
\text { or repair work on the cladding area (e.g., in the context } \\
\text { of maintenance activities), until the date of the visual } \\
\text { inspection on site. If no work has been performed, the } \\
\text { period starts from the date of the } \\
\text { building's construction. }\end{array}$ & years & - \\
\hline & $\begin{array}{l}\text { Number of } \\
\text { floors }\end{array}$ & $N f$ & $\begin{array}{l}\text { Number of floors above the ground on the side of } \\
\text { the façade. }\end{array}$ & levels & - \\
\hline & Cladding area & $\mathrm{Ca}$ & Area of the façade cladding. & $\mathrm{m}^{2}$ & - \\
\hline 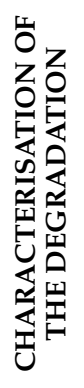 & $\begin{array}{l}\text { Severity of } \\
\text { degradation } \\
\text { index }\end{array}$ & $S_{w}$ & $\begin{array}{l}\text { Severity of degradation index }\left(S_{w}\right) \text {, which is calculated } \\
\text { through the following equation: } \\
S_{w}=\frac{\sum\left(A_{n} \times k_{n} \times k_{a, n}\right)}{A \times \sum k} \\
\text { where } S_{w} \text { is the severity of degradation (in percentage); } \\
A_{n} \text { the area affected by anomaly } n\left(\text { in }^{2}\right) ; k_{n} \text { the } \\
\text { multiplication factor for the anomaly } n ; k_{a, n} \text { the } \\
\text { weighting coefficient according to the relative weight } \\
\text { of the anomaly } n \text {; A the total area of the constructive } \\
\left.\text { solution (in } \mathrm{m}^{2}\right) ; \text { and } k \text { the multiplying factor } \\
\text { corresponding to the highest degradation condition of } \\
\text { the area } A \text {. }\end{array}$ & $\%$ & - \\
\hline \multirow{5}{*}{ 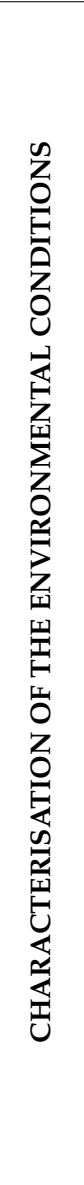 } & Orientation & Ori & $\begin{array}{l}\text { Orientation of the façade, according to the following } \\
\text { cardinal directions: North (N), East (E), South (S), and } \\
\text { West (W). The following ordinal directions are also } \\
\text { considered: Northeast (NE), Southeast (SE), Southwest } \\
\text { (SW), and Northwest (NW). } \\
\text { Variable that summarises specific factors from each } \\
\text { orientation, such as (i) prevailing winds, (ii) } \\
\text { probability of occurrence of rain-wind action, (iii) solar } \\
\text { radiation contributing to thermal variations on the } \\
\text { façade and (iv) probability of occurrence of } \\
\text { temperature and humidity conditions favourable to } \\
\text { biological colonization. }\end{array}$ & - & $\begin{array}{l}\text { N, NE, E, SE, S, SW, } \\
\text { W, NW }\end{array}$ \\
\hline & $\begin{array}{l}\text { Proximity to } \\
\text { the sea }\end{array}$ & Sea & $\begin{array}{l}\text { Distance between the façade and the coastline. } \\
\text { Indicator of (i) wind transportation of sea salts and } \\
\text { algae that colonize façades and (ii) significant } \\
\text { exposure to UV radiation and relative humidity. }\end{array}$ & - & $<5 \mathrm{~km},>5 \mathrm{~km}$ \\
\hline & Wind action & Win & $\begin{array}{l}\text { Effect of the wind on the façade. } \\
\text { The intensity depends on the (i) exposure of the façade } \\
\text { to prevailing winds and to rain-wind action, } \\
\text { (ii) protection of the façade by surrounding buildings } \\
\text { and vegetation (the more unprotected, the greater the } \\
\text { risk) and (iii) height of the building (the higher the } \\
\text { building, the greater the risk). }\end{array}$ & - & $\begin{array}{l}\text { severe, moderate, } \\
\text { mild }\end{array}$ \\
\hline & $\begin{array}{l}\text { Exposure to } \\
\text { humidity }\end{array}$ & Hит & $\begin{array}{l}\text { Relative humidity and precipitation typical of the } \\
\text { location of the façade. } \\
\text { High intensity when the prevailing winds coming } \\
\text { from the sea and the location is closer to the coast. } \\
\text { Low intensity when the location is in an urban area } \\
\text { and a long way from the sea. }\end{array}$ & - & high, low \\
\hline & $\begin{array}{l}\text { Exposure to } \\
\text { pollutants }\end{array}$ & Pol & $\begin{array}{l}\text { Pollution from traffic, mainly associated with } \\
\text { urban centres. } \\
\text { The intensity depends on the location of the building. } \\
\text { High intensity when it is close to main roads (intense } \\
\text { traffic). Medium intensity when it is close to secondary } \\
\text { roads (moderate or low traffic). Low intensity when it } \\
\text { is in rural or coastal areas. }\end{array}$ & - & high, medium, low \\
\hline
\end{tabular}

Observation: Source of information: research work developed about the service life prediction of façade claddings [1,13-15], specifically dissertations and databases files. 
The cladding area $(\mathrm{Ca})$ is below $1200 \mathrm{~m}^{2}$, in $98 \%$ of the façades. Four case studies are characterised by larger cladding areas, with the largest being $7725 \mathrm{~m}^{2}$. Around $96 \%$ of the areas are less than $400 \mathrm{~m}^{2}$ and $75 \%(Q 3)$ are less than $170 \mathrm{~m}^{2}$. It is likely that the majority of the inspected façades are common multi-floor residential buildings, which is stressed by the mean value (Table 2) and compatible with the results of the variable $N f$. The greatest area is considerably more than most of the areas in the sample, which may indicate the presence of a possible outlier, and it was found for a public church building. The sample is characterised by considerable dispersion and heterogeneity, considering the standard deviation $(\hat{\sigma}=580.6)$ and the coefficient of variation $(C V=325.2 \%)$. The skewness is positive $(\gamma>0)$, having a longer tail on the right side.

Table 2. Descriptive statistics of the quantitative variables.

\begin{tabular}{|c|c|c|c|c|c|c|c|c|c|c|c|c|c|}
\hline Variable & $\hat{\mu}$ & $\begin{array}{l}\text { Mode/Mode } \\
\text { Class }\end{array}$ & Median & $\hat{\sigma}$ & Minimum & Maximum & Range & Q1 & Q3 & IQR & $\begin{array}{l}\mathrm{CV} \\
(\%)\end{array}$ & $\hat{\gamma}$ & $\hat{k}$ \\
\hline$A g$ & 14.7 & until 5 & 9.0 & 15.8 & 0.0 & 89.0 & 89.0 & 4.0 & 19.8 & 15.8 & 107.3 & 1.9 & 3.8 \\
\hline$N f$ & 5.0 & 5.0 & 5.0 & 2.8 & 1.0 & 16.0 & 15.0 & 3.3 & 5.0 & 1.8 & 56.1 & 1.5 & 3.2 \\
\hline $\mathrm{Ca}$ & 178.3 & until 50 & 70.0 & 580.6 & 0.8 & 7724.7 & 7723.9 & 31.2 & 170.0 & 138.8 & 325.2 & 10.7 & 126.6 \\
\hline$S_{w}$ & 9.5 & until 5 & 3.5 & 13.3 & 0.0 & 71.6 & 71.6 & 1.7 & 10.9 & 9.2 & 139.4 & 2.3 & 5.2 \\
\hline
\end{tabular}

The highest severity of degradation index $\left(S_{w}\right)$ observed is of $71.6 \%$, which is a long way from the $10 \%$ mean and Q3 (Table 2). For $10 \% S_{w}$, the cladding is considered to be in good condition or with slight degradation $[1,14,15]$. This degradation level is likely associated with younger façades [13], which suggests that the sample is characterised by young ages. The $S_{w}$ of $97 \%$ of the façades is lower than $50 \%$. The cladding is expected to reach the end of service life for $S_{w}$ between $20 \%$ and $30 \%$, depending on the material. Therefore, it is possible that $17 \%$ of the sample is in that condition. The generalized degradation of the cladding is assumed for $S_{w}$ values above the 30\% to $50 \%$ range, depending on the material $[1,14,15]$. Therefore, $8 \%$ of the façades can be included in the worst category of degradation condition. The sample is characterised by a significant dispersion and heterogeneity, considering the standard deviation $(\hat{\sigma}=13.3)$ and the coefficient of variation $(C V=139.4 \%)$. The skewness is positive $(\gamma>0)$, having a longer tail on the right side, where the case studies in worse degradation condition are observed.

The scatterplot matrix of the quantitative variables (Figure 2) reveals that the dispersion of the variables $A g$ and $S_{w}$ is the closest to the simple linear regression (SLR) trend line. The other combinations of variables result in dispersions that do not follow the suggested trend line. The moderate correlation between $A g$ and $S_{w}$ is the most effective, according to the highest Pearson correlation coefficient $(r)$ of 0.513 . The scatterplot matrix highlights the existence of possible outliers, related to the variable $\mathrm{Ca}$.

\subsection{Characterization of Qualitative Variables}

Table 3 shows the descriptive univariate analysis of the qualitative variables analysed in this study. All the variables, except $M a$, characterize the environmental exposure conditions of the façades analysed.

The environmental variables are complex since (i) they cover the simultaneous action of a set of climate parameters, (ii) the categories can be associated with the context or location of the façade (Table 1), and (iii) the characterization of some of the variables includes aspects related to other variables (Table 1), since they are somehow interconnected.

The cardinal orientations are represented in similar proportions in the sample, despite the slightly higher frequency of façades facing $\mathrm{N}$ and $\mathrm{W}$. N and $\mathrm{W}$ oriented façades are more prone to suffer higher degradation levels due to higher exposure to the combined action of wind and air humidity [5].

The 'Sea' categories are almost evenly represented in the sample. Approximately, $52 \%$ of the façades are located less than $5 \mathrm{~km}$ from the coast. The distance from the sea is an aggravating factor for the environmental degradation of the claddings, as well as 
strong wind and high humidity exposure [21]. Most of the sample is exposed to moderate wind, which likely indicates that these façades are protected by surrounding buildings or vegetation, are not near to the coast, and are not installed on tall buildings. However, around $29 \%$ of the case studies are subjected to strong wind action, which is a considerable source of damage to constructions [22]. A significant part of the sample, corresponding to $40 \%$, is exposed to high relative humidity and is located near the coast.

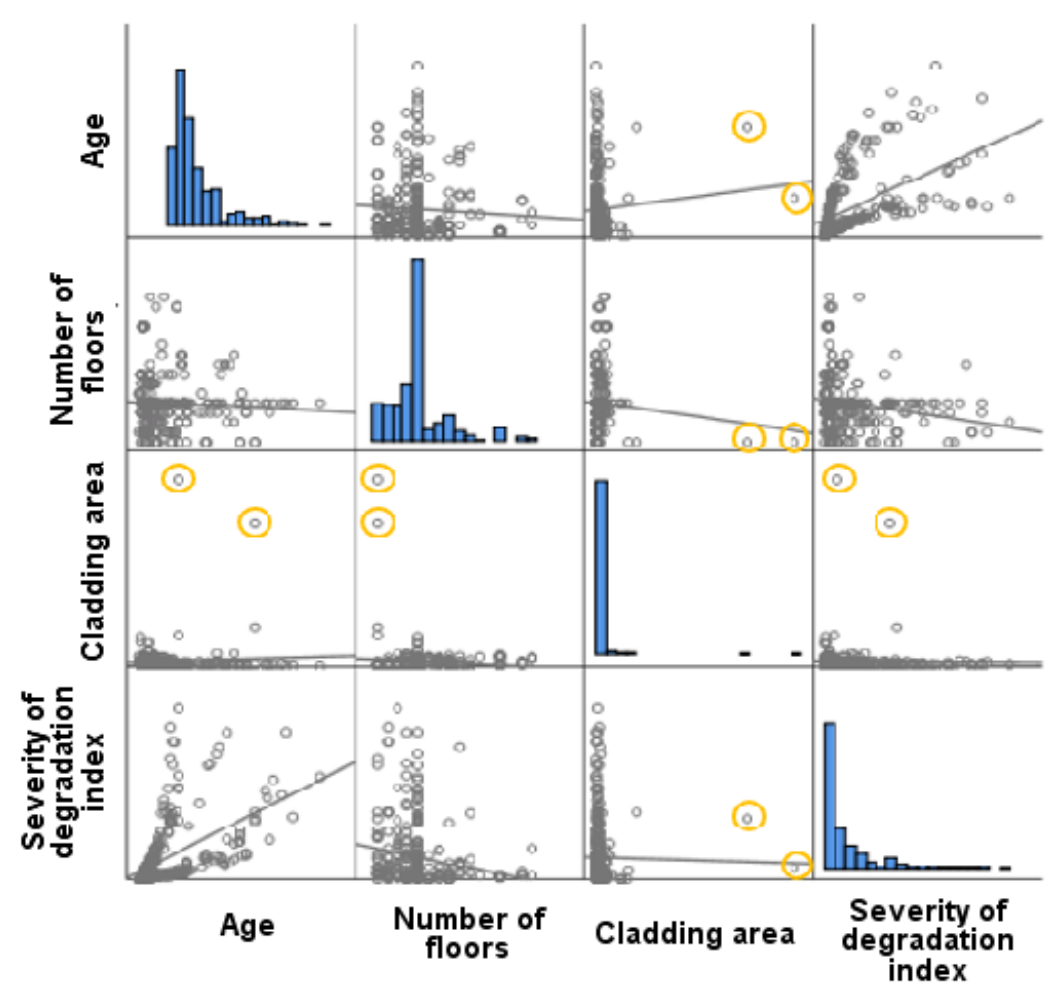

Figure 2. Scatterplot matrix of the combinations between quantitative variables with the identification, in yellow, of possible outliers associated with the variable $\mathrm{Ca}$.

Despite being an environmental exposure variable, ' $\mathrm{Pol}$ ' is not directly related to climate agents. Nevertheless, the influence of pollution on the degradation of cladding is combined with climate parameters. The exposure to pollutants aggravates the degradation of façades [23]. Most of the sample, corresponding to $72 \%$, is located near main roads and exposed to pollution caused by intense traffic.

This study comprises all the types of façade cladding in one comprehensive sample. However, the variable ' $\mathrm{Ma}$ ' that characterizes the diversity of materials in the sample allows a comparative analysis of the environmental exposure variables impact on the different claddings.

\section{Data Analysis}

\subsection{Factorial Analysis}

Principal Components Analysis (PCA) enables the data contained in the variables to be summarised into a smaller set of factors, while losing as little information as possible. The pre-dominance of categorical variables is evident, which is not useful for PCA. Therefore, each of the following variables must be transformed into a dummy variable: $M a$, Ori, Sea, Win, Hum, and Pol. Unlike these variables, the quantitative variables need to be standardized to become dimensionless, since they are expressed in different units (e.g., $S_{w}$ in $\%$ and $\mathrm{Ca}$ in $\mathrm{m}^{2}$ ). The creation of the principal components depends on the critical analysis of the following criteria: (i) the components must explain a considerable amount of the total variance, where $70 \%$ is the cumulative variance value of reference, (ii) only the components with eigenvalues superior to 1 are chosen, according to the Kaiser criterion, 
and (iii) only the components to the left of the "elbow", in the scree plot, are considered significant. The results are not conclusive since the components do not significantly explain the dummy variables. Quantitative variables $S_{w}$ and $A g$ are consistently grouped in the same component. The PCA of just the quantitative variables $\left(A g, N f, C a\right.$, and $\left.S_{w}\right)$ results in three components, the first also grouping the variables $S_{w}$ and $A g$.

Table 3. Descriptive statistics of the qualitative variables.

\begin{tabular}{|c|c|c|c|}
\hline Variable & & $\begin{array}{c}\text { Percentage of Case } \\
\text { Studies }\end{array}$ & Frequency \\
\hline \multirow{6}{*}{ Material $(M a)$} & $R$ & $16.7 \%$ & 50 \\
\hline & NSC & $16.7 \%$ & 50 \\
\hline & CTS & $16.7 \%$ & 50 \\
\hline & PS & $16.7 \%$ & 50 \\
\hline & ETICS & $16.7 \%$ & 50 \\
\hline & $A C F$ & $16.7 \%$ & 50 \\
\hline \multirow{8}{*}{$\begin{array}{l}\text { Orientation (Ori) } \\
\quad \text { Mode }=N\end{array}$} & $N$ & $22.3 \%$ & 67 \\
\hline & $N E$ & $8.0 \%$ & 24 \\
\hline & $E$ & $17.0 \%$ & 51 \\
\hline & $S E$ & $4.7 \%$ & 14 \\
\hline & $S$ & $16.3 \%$ & 49 \\
\hline & $S W$ & $4.7 \%$ & 14 \\
\hline & $W$ & $21.7 \%$ & 65 \\
\hline & $N W$ & $5.3 \%$ & 16 \\
\hline Proximity to the sea (Sea) & $<5 \mathrm{~km}$ & $51.7 \%$ & 155 \\
\hline Mode $=<5 \mathrm{~km}$ & $>5 \mathrm{~km}$ & $48.3 \%$ & 145 \\
\hline \multirow{3}{*}{$\begin{array}{l}\text { Wind action }(\text { Win }) \\
\text { Mode = Moderate }\end{array}$} & Mild & $25.3 \%$ & 76 \\
\hline & Moderate & $46.0 \%$ & 138 \\
\hline & Severe & $28.7 \%$ & 86 \\
\hline \multirow{2}{*}{$\begin{array}{l}\text { Exposure to humidity }(\mathrm{Hum}) \\
\text { Mode = Low }\end{array}$} & Low & $60.7 \%$ & 182 \\
\hline & High & $39.3 \%$ & 118 \\
\hline \multirow{3}{*}{$\begin{array}{l}\text { Exposure to pollutants }(\mathrm{Pol}) \\
\quad \text { Mode }=\text { Moderate }\end{array}$} & Low & $8.7 \%$ & 26 \\
\hline & Medium & $72.3 \%$ & 217 \\
\hline & High & $19.0 \%$ & 57 \\
\hline
\end{tabular}

Categorical Principal Components Analysis (CATPCA) is more useful to this study, considering the predominance of qualitative variables. The most coherent results are obtained for six components, excluding the variable $\mathrm{Ma}$, which have the following distribution:

- Component 1-degradation condition of the façade cladding ( $S_{w}$ and $A g$ );

- Component 2-aerial environmental actions (Win and Pol);

- Component 3-coastal environmental actions (Sea and Hum);

- Component 4-characterization of the building height ( $\mathrm{Nf}$ );

- Component 5-exposure to the sun (Ori);

- Component 6-characterization of the cladding area $(\mathrm{Ca})$.

Despite the slight reduction of the number of variables into components, it can be seen that the variables grouped in the same component are logically related. The age $(A g)$ of the façade is determinant to its degradation condition $\left(S_{w}\right)$, since the degradation phenomenon evolves over time. However, age is not the defining aspect itself of the degradation. Over time, claddings are subjected to the cumulative action of degradation agents $[9,24,25]$. The greater the age, the longer the exposure period of the cladding, and a more severe degradation condition is expected [26,27], in the absence of maintenance actions. The wind (Win) contributes to the transportation of particles in the air, from traffic pollution (Pol), and affects their deposition rate on façades, as well as the coverage area and the soiling intensity [28]. The relative humidity (Hum) is likely higher in coastal areas (Sea) [15]. 


\subsection{Cluster Analysis}

Cluster Analysis (CA) allows splitting the sample into homogeneous groups, formed by similar entities, which are different from each other. In the present study, CA is developed mostly through hierarchical methods, based on (i) the components resulting from the PCA and the combination of different variables, (ii) the various distance measurements (Euclidean squared distance, city-block, Chebyshev, and Minkowski) and aggregation criteria (centroid, the closest neighbour, group average, and Ward).

Some of the CA results lead to single object clusters and thus to cluster formations that do not explain the sample's behaviour. However, in one of them (variables $S_{w}$ and $A g$ with Euclidean squared distance and centroid aggregation-four clusters), two of the groups resulting from the clustering process seem to organise the façades according to the durability and characteristics of the materials. The number of clusters to retain, using hierarchical methods, is determined mainly by the analysis of the linkage distance in the dendrogram. Nevertheless, the possibility of experimenting with a different number of clusters is not excluded for studying the relations between the clusters and the claddings' durability.

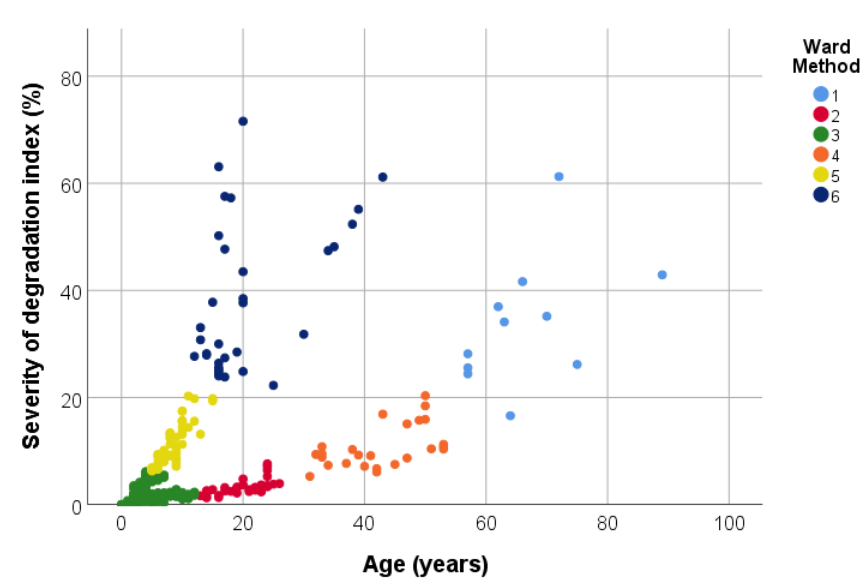

(a)

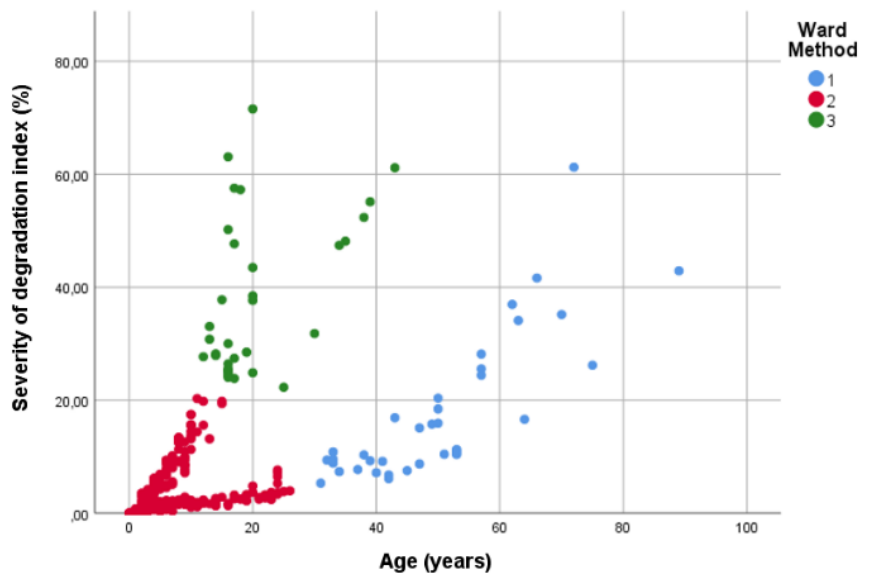

(b)

Figure 3. Scatterplot of the variables $S_{w}$ and $A g$ with the identification of the six clusters (a) and three clusters (b) (city-block distance and Ward aggregation).

A further analysis leads to the creation of six multi-object clusters (variables $S_{w}$ and $A g$ with city-block distance and Ward aggregation), which stresses the grouping of façades with similar durability claddings (Figure 3a). Group I (clusters 1, 2 and 4) includes NSC, CTS, and ACF. Group II (clusters 5 and 6) includes R, PS, and ETICS. Each group is characterised by materials with similar degradation behaviour over time, where claddings in group I are more durable and those in group II less durable. Cluster 3 includes all the cladding types and the youngest ( $\mathrm{Ag}$ mean 4.7 years) and less degraded $\left(S_{w}\right.$ mean $\left.1.9 \%\right)$ façades. At young ages, the behaviour of the six materials is more similar, but the bifurcated dispersion indicates a tendency of two different degradation behaviours with age. The dispersion is higher in clusters 1 and 6 than in clusters 2 and 5, which suggests that the claddings in each cluster tend to have increasingly distinct behaviours the closer they are to the degradation threshold. Moreover, each cladding's degradation is likely to be more scattered with age.

The Bonferroni test is used to validate the independence between clusters. Despite the interesting results, the test reveals that the six clusters are not all significantly different. The creation of three clusters (Figure $3 b$ ), based on the same method, was tested and in this case the difference between the groups has been proved. Clusters 1 and 3 (Figure 3b) also group the claddings according to their durability and characteristics. However, this solution increases the number of façades with younger ages and less degradation, included in cluster 2 (Figure 3b). The previous clustering (Figure 3a) allows a more detailed analysis of the claddings, in particular the younger and less degraded ones. 


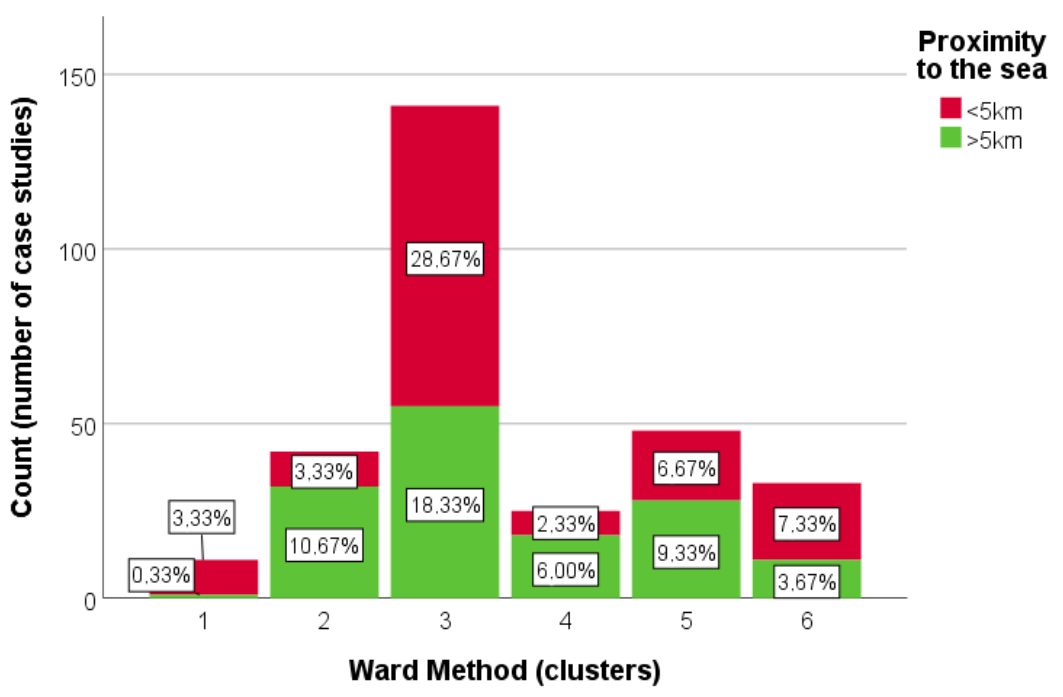

(a)

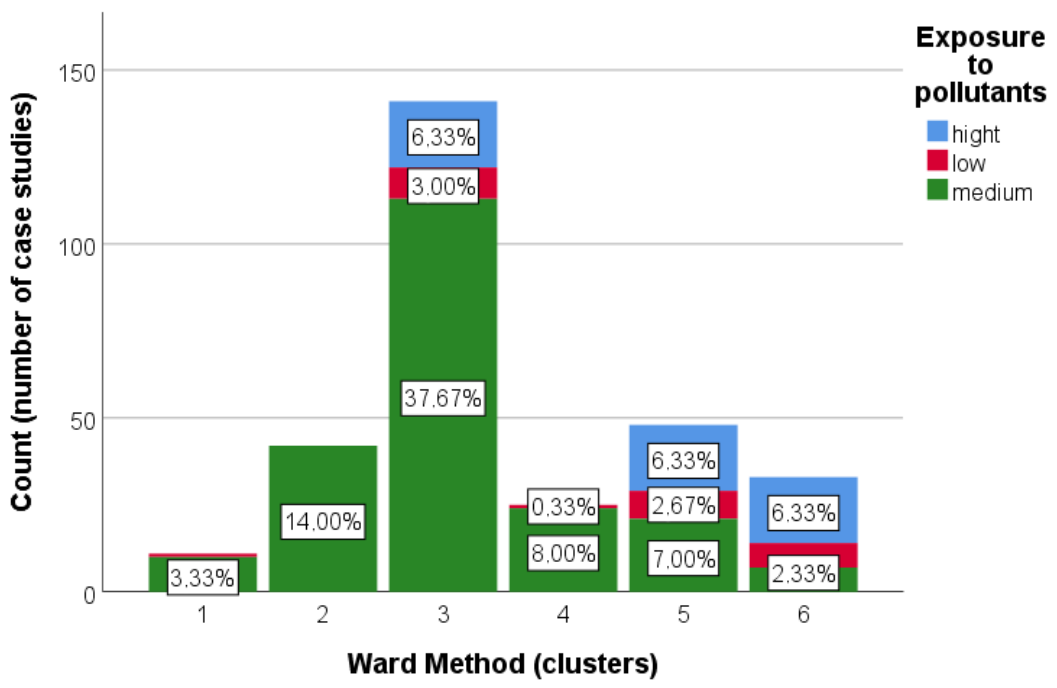

(b)

Figure 4. Detailed analysis of the six clusters presented in Figure $3 a$, according to the qualitative variables Sea (a) and Pol (b).

A comprehensive study of the clusters on Figure 3a shows that group II (clusters 5 and 6) has more façades facing north than group I (clusters 1, 2 and 4). This is one of the orientations more susceptible to degradation and expected to be characterised by higher $S_{w}$ values, due to the lack of sun exposure and the longer moisture cycles [5]. In addition, in group II, the number of façades closer to the coast and exposed to high pollution levels is higher than in group I (Figure 4a,b). Proximity to a saline environment can contribute to severe degradation levels [5]. The maintenance and rehabilitation costs due to air pollution are more significant in urban and industrial areas [23], characterized by high pollution levels. These results indicate that the vulnerability to environmental degradation can be higher for group II (Figure $4 \mathrm{~b}$ ), which helps to increase the $S_{w}$ value of the case studies in this group.

A close examination of the cluster analysis results reveals that the materials tend to be grouped according to their durability and organised in more durable and less durable cladding solutions. In addition, a complementary detailed analysis suggests that the environmental variables probably contribute to the decreased durability of R, PS and ETICS. 


\subsection{ANOVA Test}

The ANOVA test is used to check whether an independent factor has any influence on the dependent variable $S_{w}$. In this study, the effect of the environmental exposure variables on the degradation of façade claddings is analysed, specifically on the average value of $S_{w}$. The results of the performed ANOVA tests are:

- Ori-the influence is not confirmed for the whole sample, but this variable seems to have some influence specifically on the degradation of NSC and ACF; the high number of categories (cardinal and ordinal orientations) hinders the interpretation of the results;

- $\quad$ Sea - the influence is not confirmed for the whole sample, but this variable seems to have some influence specifically on the degradation of R, PS, and CTS; it can be explained by (i) the significant $S_{w}$ mean of the façades in the " $<5 \mathrm{~km}$ " exposure category of R and CTS, and (ii) the unexpected significant $S_{w}$ mean of the façades in the " $>5 \mathrm{~km}$ " category of PS; the $S_{w}$ mean is higher for the most severe category of this variable, as expected;

- Win - the influence is confirmed for the whole sample and specifically in PS, ETICS, and ACF; it can be explained by (i) the significant $S_{w}$ mean of the façades in the "severe" exposure category of ACF, (ii) the higher $S_{w}$ mean of the façades in the "severe" exposure category of ETICS compared to the "mild", and (iii) the unexpected significant $S_{w}$ mean of the façades in the "mild" category of PS; the $S_{w}$ mean is higher for the least severe category of this variable, which is unexpected;

- Hum - the influence is not confirmed for the whole sample, but this variable seems to have some influence specifically on the degradation of PS and NSC; it can be explained by the unexpected significant $S_{w}$ mean of the façades in the "low" exposure category of PS (the $S_{w}$ mean is higher for the least severe category of this variable);

- Pol-the influence is verified for the whole sample and specifically in PS, which can be explained by the significant $37.1 \% S_{w}$ mean of the façades in the "high" exposure category; the $S_{w}$ mean is higher for the most severe category of this variable, as expected.

The ANOVA test of categorical variable Mat confirms its influence on $S_{w}$. The mean values of $S_{w}$ per cladding type emphasise the division of the sample in groups I (NSC, CTS, and ACF) and II (R, PS, and ETICS), since the proximity of the values is evident for the materials in each group.

The results of the ANOVA tests on the environmental exposure variables do not fully explain the expected relation between these variables and the degradation of façade claddings. However, the influence of the environmental context and agents is confirmed for specific materials, when not for the whole sample.

\subsection{Multiple Regression}

The multiple linear regression (MLR) model allows checking how several independent variables explain the dependent variable $S_{w}$. The environmental exposure variables can be included in this model, as dummy variables. Initially, two models are tested, through enter and stepwise methods, including only the quantitative variables $A g, N f$, and $C a$. The adjusted determination coefficients (adjusted $\mathrm{R}^{2}$ ) are similar and both models explain only $29 \%$ of the dependent variable, approximately. The significance of the variable $\mathrm{Ca}$ to the explanatory capacity to the model is low and possibly hindered by the presence of possible outliers (as mentioned in Section 4.1, Figure 2). Another model is tested, using the "enter" method, including all the qualitative variables too, converted into dummy variables. In this model, the adjusted $\mathrm{R}^{2}$ increased, and the model explains around $61 \%$ of the $S_{w}$, which means that the environmental exposure variables add explanatory capacity to the model.

After considering the results of the previous models, excluding multicollinearity problems, and taking into account the performed ANOVA tests (Section 5.3), a new model is tested excluding the $\mathrm{Ca}$ and the dummy variables Ori and Hum. This model still explains around $61 \%$ of the dependent variable and is free from multicollinearity problems. In 
the analysis of the residuals, the heteroscedasticity of the model for the variables $S_{w}$ and $A g$ is observed, as well as the non-normal distribution of the residuals, according to the results of the Kolmogorov-Smirnov test. However, the Spearman and Durbin-Watson tests confirmed the independence of the residuals, contributing to a partial validation of the model. The analysis of the standardised beta weights confirms the significant influence of the $\mathrm{Ag}$ in in the model. In addition, the analysis reveals that (i) exposure to a high pollution level tends to increase the degradation of the façade, and (ii) a greater distance to the coast contributes to decrease it. The claddings in group I (NSC, CTS, and ACF), considered as more durable materials, have negative standardised beta weights, associating these façades with less severe degradation conditions and a presumably increased durability.

Finally, the claddings are individually analysed. The only MLR model that does not present multicollinearity problems includes the independent variables $A g$, Sea, and Win. The environmental exposure variables used increase the explanatory capacity of the model only for the materials NSC, ACF, and ETICS, compared with the SLR model ( $S_{w}$ and $A g$ ). The analysis of the standardised beta weights reveals that not only for these materials, but also for CTS and PS, a greater distance to the coastline tends to result in less degradation of the façades and increase their durability.

The MLR models do not validate the importance of all the environmental variables to the degradation of the claddings. However, the importance of the environmental context and agents is verified for the whole sample and for specific materials.

\section{Discussion of the Results}

Prior to deepening the knowledge on the impact of environmental exposure conditions, it is important to understand that the correlation between $S_{w}$ and $A g$ is the basis for perceiving the façade claddings' degradation evolution over time. $S_{w}$ and $A g$ are the most correlated quantitative variables, as expected and excluding pre-pathology symptoms. In addition, the cladding type (Mat) is determinant to characterize the degradation pattern. The façade's performance and expected end-of-service life depend on the material.

The relation between $S_{w}$ and the cladding types (Figure 5) shows that CTS and NSC are characterised by lower degradation conditions than the other materials. The $S_{w}$ of $75 \%$ of the CTS and NSC samples goes up to a maximum of $4 \%$ and $6 \%$, respectively. On the other hand, PS are noted for a more accentuated severity of degradation with the $S_{w}$ of $75 \%$ of the painted façades going up to $20 \%$. CTS and NSC not only tend to present the most favourable degradation conditions (lower degradation indexes in the degradation scale adopted), but also tend to be more durable and perform better over time. While PS start with a $S_{w}$ above $20 \%$ after the first 10 years, CTS and NSC reach a similar state only after approximately 50 years (Figure 1). A painted façade will likely need more maintenance over time to extend the service life and to be in similar conditions to the more durable claddings, as expected. Despite ACF having a similar median $S_{w}$ to CTS and NSC, around $2 \%$, half of the façades are younger than those cladded with the other two materials. This suggests that ACF would reach similar degradation levels to CTS and NSC sooner.

The SLR of the sample divided in groups I (NSC, CTS, and ACF) and II (R, PS, and ETICS), i.e., into more and less durable materials respectively, as defined in the cluster analysis, results in higher determination coefficients $\left(R^{2}\right)$ (Figure 6). The model explains $84 \%$ of the variability of the claddings' $S_{w}$ in group I and $79 \%$ in group II, approximately. This suggests that acknowledging the durability of materials prior to the sample definition may lead to more accurate results on the environmental degradation behaviour of façade claddings.

The results of the ANOVA tests do not confirm the influence of 'Ori' on the dependent variable $S_{w}$ for the whole sample, which is an unexpected result. However, the influence is confirmed for NSC and ACF. The orientation is known to be determinant to the occurrence of defects in external claddings, particularly in painted rendered façades [29]. Also, the specific analysis of variables $S_{w}$ and Ori for the whole sample reveals that south shows less degraded claddings than north, with the latter is characterized by higher $S_{w}$ values 
(Figure 7). The considerable degradation of NE-oriented façades could be related to the older age of the claddings of this part of the sample.

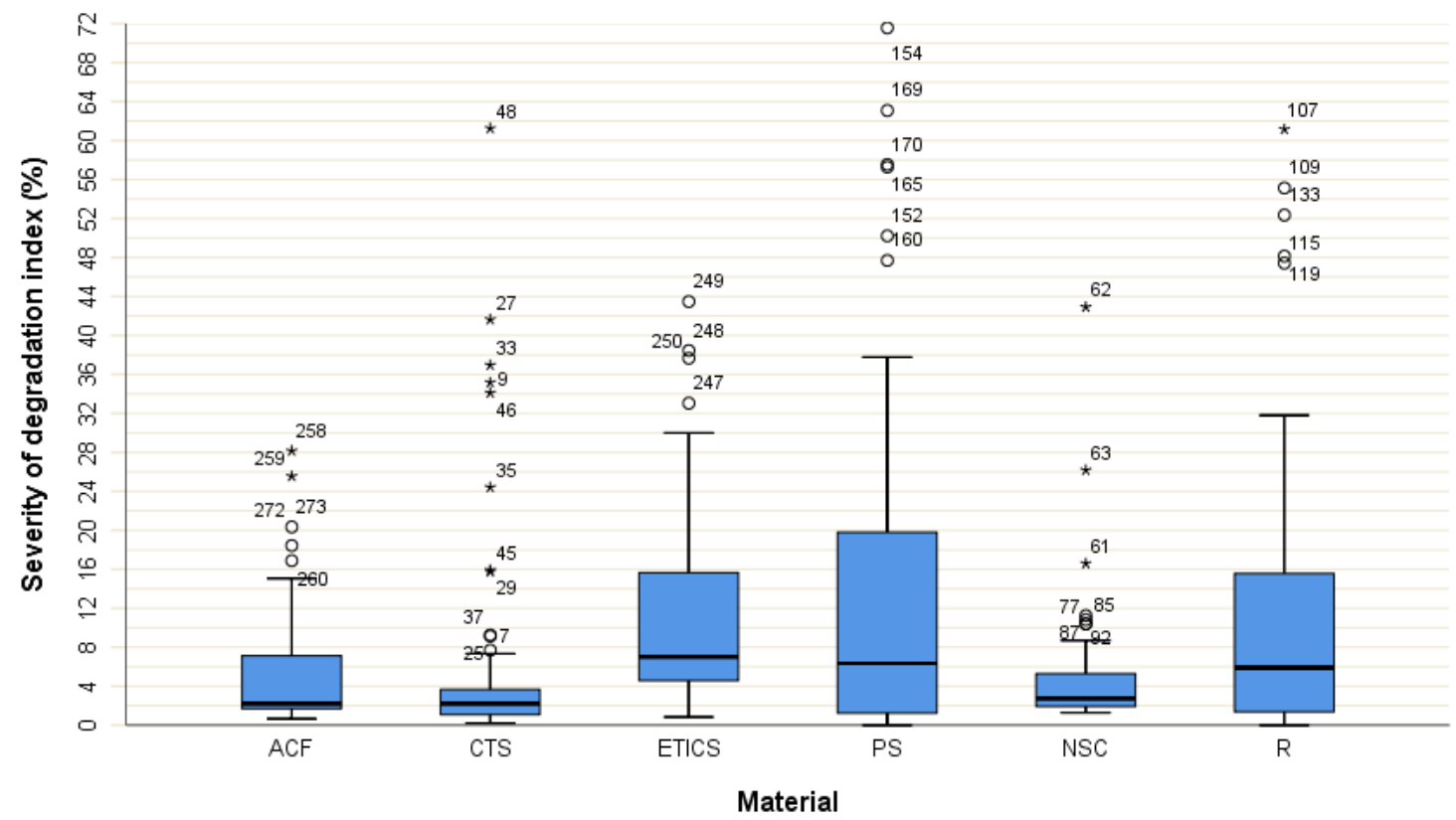

Figure 5. Box plot of $S_{w}$ and Mat (circles are possible outliers and stars faroutliers, above the 75th percentile).

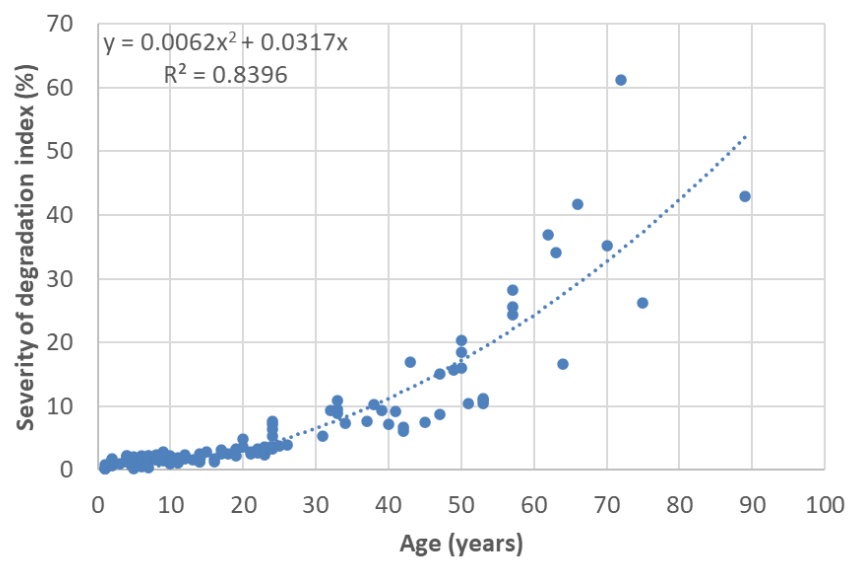

(a)

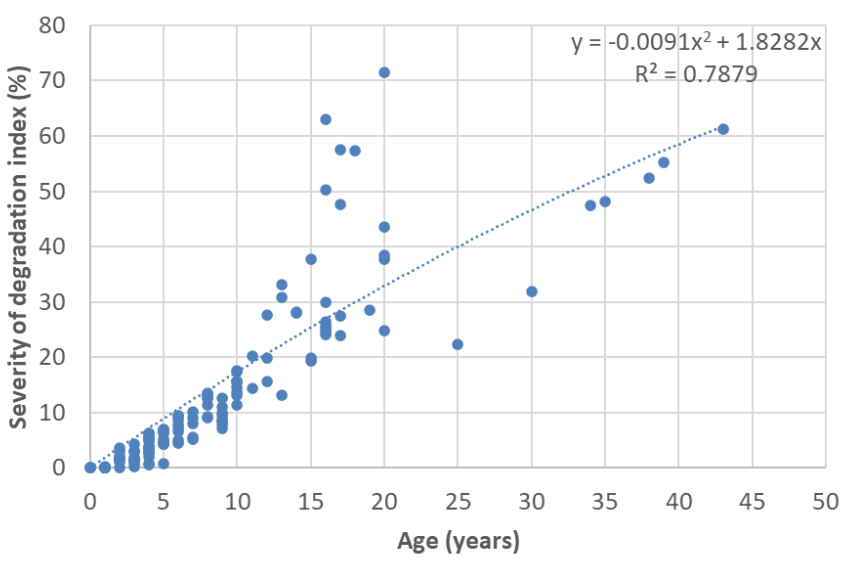

(b)

Figure 6. Scatterplot of the variables $S_{w}$ and $A g$ for group I (a) and group II (b).

'Ori' is a complex variable, which probably influences the microclimate of the façade, important to the growth of the façade's environmental degradation [3,4]. It combines the exposure to prevailing winds and the period and intensity of solar radiation, which affect the transportation of biological and pollution particles, rain-wind action, the temperature of the material, and the occurrence and drying of moisture on the surface and/or damp in the microstructure of the material $[8,30]$.

The presence of damp is one of the main environmental actions causing defects on ETICS [31] and painted rendered walls [32]. The north orientation is characterized by the lack of exposure to solar radiation and longer wetting periods. These conditions are favourable for the presence of damp in the cladding and, consequently, for the development of biological colonization. Damp also causes soiling stains, essentially because it works as an adhesive for dirt particles [32]. Despite the inconclusive ANOVA tests' results, the less durable claddings (R, PS, and ETICS) are represented by more case studies facing north 
than the rest of the sample, as demonstrated by the comprehensive study of the clusters' formation. Therefore, it is possible that the north orientation contributes to the increased degradation $\left(S_{w}\right)$ and the decreased durability of this group of materials.

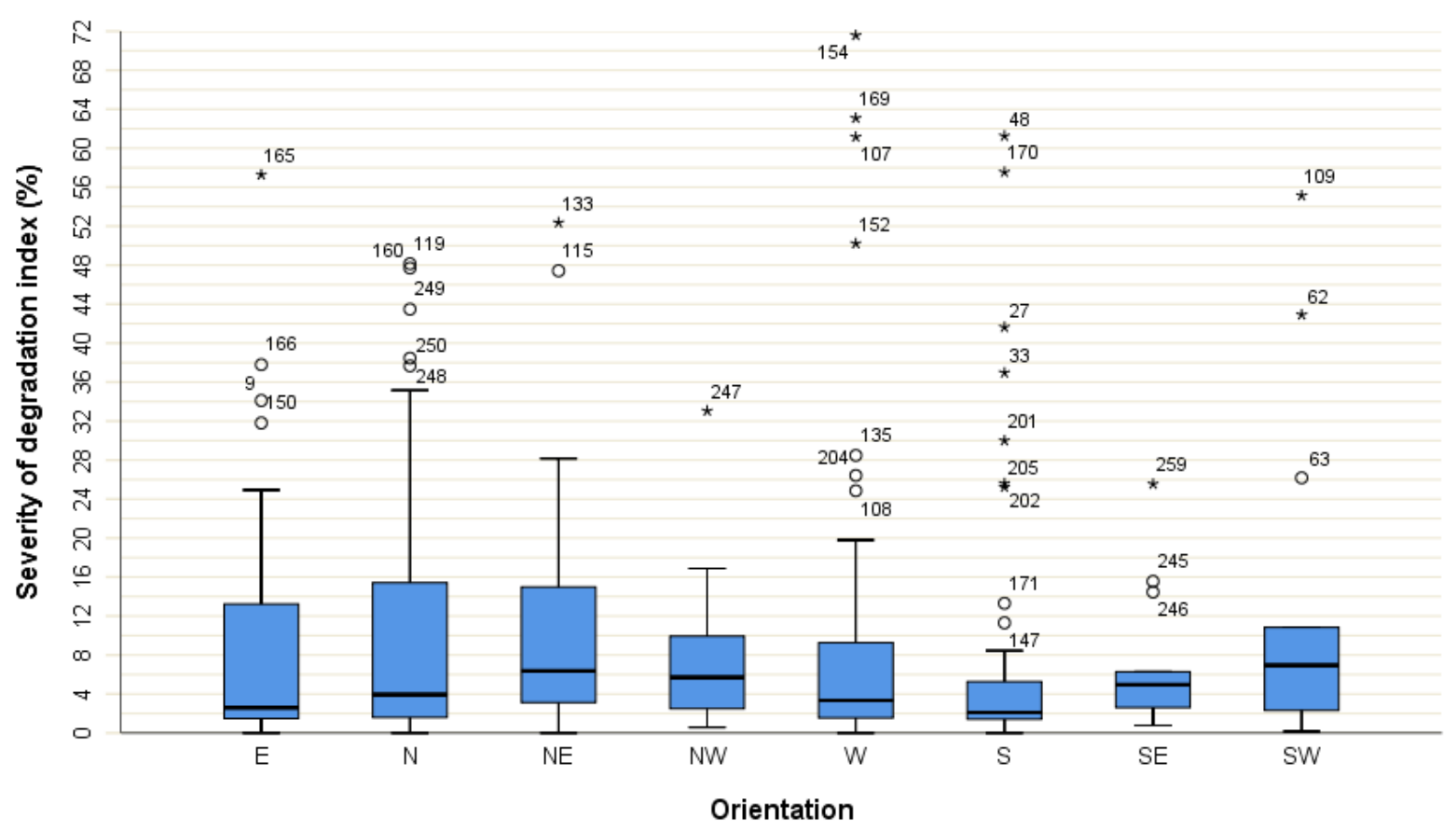

Figure 7. Box plot of $S_{w}$ and Ori (circles are possible outliers and stars faroutliers, above the 75th percentile).

The degradation is expected to be characterised by different predominant types of defects, depending on the climate action associated with each orientation. The ETICS degradation is characterised by biological colonization on north-oriented façades and by loss of colour and cracking on façades facing south [14]. The same occurs for PS, including soiling stains on north façades [29]. On the one hand, the complexity of the variable 'Ori' makes it relevant to the characterization of existing degradation; on the other hand, the nuances of orientation associated with the ordinal directions possibly hinders the analysis of its influence on the degradation condition $\left(S_{w}\right)$, in the present study.

The unexpected results of the ANOVA tests for PS, regarding the significant $S_{w}$ means for the least severe categories of the variables 'Sea' (>5 km), 'Win' (mild) and 'Hum' (low), can be a consequence of the reduced predicted service life difference between categories. The predicted service life is not greatly different for the most and the least severe categories of these environmental variables. The difference is less than one year [33]. Within the context of the present study, the initial sample reduction could have been enough to distort the mean values of the variables' categories. In addition, the PS condition evolves rapidly, and the service life is reduced, compared with the other claddings. It can be assumed that PS are vulnerable to considerable degradation progress in a short period, despite the environmental exposure.

The results from the MLR analysis stress that the distance to coastal areas leads to less degradation and greater durability of the claddings. This result is consistent with previous research on the degradation of NSC, CTS, and PS, confirming that the claddings closer to the sea are more prone to be in a serious condition or to reach it sooner [34]. The saline fog spray typical of coastal areas is an aggressive degradation agent for limestone façade cladding in particular, as is the presence of humidity [35]. These conditions can accelerate the degradation process of claddings [36], thereby reducing the service life of façades. The degradation agents in marine environments lead to the early degradation of external claddings [37]. In addition, the degradation of architectural concrete surfaces can be faster in buildings located in coastal areas, due to the significant presence of humidity [38]. 
As revealed by the MLR analysis, exposure to air pollution contributes to the degradation of buildings [39]. Traffic increase, as well as industrialization in developing countries, can be a counteracting factor to recent reductions in some pollutants' emission rates. Traffic is a great contribution to a changing multi-pollutant environment [40]. Pollution from traffic emissions (i.e., $\mathrm{CO}, \mathrm{SO}_{2}, \mathrm{NO}_{2}, \mathrm{NO}_{\mathrm{x}}$, and $\mathrm{PM}_{10}$ ) that are greater in urban areas is a serious problem for the degradation of historical buildings' façades [41]. Air pollution accelerates the degradation rate of several materials, leading to costly maintenance needs with more frequent interventions. The salts resulting from the reaction between the pollutants and the stone are the most damaging pollution-related agents of degradation. The formation of gypsum and the dissolution of carbonate are the main pollution-induced mechanisms of degradation. Acid rain, caused by air pollutant contamination, penetrates the pore structure of the stone, leading to its disintegration by chemical reaction. The accumulation of salts in the pores happens over time, resulting in long-term effects of the exposure to air pollution [42]. Traffic pollution is proven to be a dominant source of particulate matter components (PHAs) in black crusts [41].

The rate of the air pollution attack of concrete is slower than for calcareous stones. The best-known effect on concrete is the carbonation, due to a chemical reaction with atmospheric $\mathrm{CO}_{2}$. The increase of $\mathrm{CO}_{2}$ in the atmosphere is a direct consequence of increasing fossil fuel combustion [42]. The carbonation can result in premature failure of the protective concrete covering the reinforcing steel and consequent corrosion and spalling. The high level of $\mathrm{CO}_{2}$ in the atmosphere serves to increase the amount of carbonic acid in precipitation, which affects the degradation of concrete [6]. Air pollution is one of the sources of salts contained in the water, which can infiltrate the pore structure of a mortar and also contribute to rendering degradation. Certain bacteria that can damage mortars are mostly found in polluted environments [43].

\section{Conclusions}

A methodology is proposed, in the present study, to analyse the impact of environmental exposure variables on the service life of façade claddings. The methodology covers the degradation $\left(S_{w}\right)$ of different claddings (R, NSC, CTS, PS, ETICS, and ACF) with a variety of ages $(A g)$, located in the same city. The sample is analysed through the (i) characterisation of the quantitative $\left(\mathrm{Ag}, \mathrm{Nf}, \mathrm{Ca}\right.$, and $\left.\mathrm{S}_{w}\right)$ and qualitative (Ma, Ori, Sea, Win, Hum, and Pol) variables, (ii) factorial analysis, (iii) cluster analysis, (iv) ANOVA tests, and (v) simple and multiple linear regressions.

The methodology developed for the service life prediction of cladding materials was developed in previous research [1,12-15]. A model with the distribution of the case studies, according to $S_{w}$ and $A g$, shows a trend line for the degradation evolution of a specific type of cladding, based on the inspection of in-service façades. The model allows predicting the service life of a specific cladding type, depending on its degradation condition. The present study confirms the importance of the cladding's age to its degradation condition, through the demonstrated positive correlation between the variables $S_{w}$ and $A g$. The results show that the degradation evolves with age, as expected.

The cladding material $(M a)$ is determinant to the façades' degradation patterns and their expected service life. The claddings can be organized in two groups, based on this assumption and according to the results of SLR and CA. Group I (NSC, CTS, and ACF) includes the most durable materials, which are expected to have a longer service life and need less maintenance than the claddings in group II (R, PS, and ETICS). The sample is characterized by two distinct degradation profiles. A further analysis of each group, dividing the sample into two, could lead to more precise results on the environmental degradation of the various claddings.

The impact of environmental exposure variables on the service life of façade claddings is confirmed by the CA, ANOVA tests, and MLR. The ANOVA tests reveal that variables 'Win' and 'Pol' have influence on the $S_{w}$ mean for the whole sample. Variables 'Ori', 'Sea', and ' $H u m^{\prime}$ ' affect the $S_{w}$ mean only for specific claddings, depending on the environmental 
variable. According to CA, locations less than $5 \mathrm{~km}$ from the sea and exposed to high air pollution levels may contribute to the loss of durability in the less durable materials-group II (R, PS, and ETICS). In addition, the high exposure to air pollutants probably increases the cladding's degradation and a more distant location from the sea probably decreases it, considering the MLR results. MLR confirms the association of the claddings in group I (NSC, CTS, and ACF) with less severe degradation conditions, which may indicate a longer service life. The present study's findings are consistent with existing literature on the influence of environmental variables on the degradation of façades. This validates the general value of results despite the location of the case studies. Nevertheless, some environmental variables combine the action of several climate agents and climate induced degradation is a complex phenomenon, which could be susceptible to local and microenvironmental conditions.

The study of the combined action of climate agents' impact on the degradation of in-service façade claddings is a fruitful path of research. Environmental variables are somehow interconnected and the action of some agents is likely more effective in the presence of others. The orientation of the façade may be the variable that reflects more precisely the microclimate of the cladding. Further analysis of the relation between façade orientation and the claddings' durability may be useful to deepen the knowledge on environmental degradation and unravel its complexity. The results could well contribute to the research on the impact of climate change on the service life of façades'.

Author Contributions: Conceptualization, J.B., I.S.D., A.S., J.d.B., I.F.-C. and A.T.; methodology, J.B. and I.S.D.; software, J.B. and I.S.D.; validation, J.B. and I.S.D.; formal analysis, J.B. and I.S.D.; investigation, J.B., I.S.D., A.S., J.d.B., I.F.-C. and A.T.; writing-original draft preparation, J.B. and I.S.D.; writing-review and editing, J.B., I.S.D., A.S., J.d.B., I.F.-C. and A.T. All authors have read and agreed to the published version of the manuscript.

Funding: This research was funded by FCT (Portuguese Foundation for Science and Technology) through the project BestMaintenance-LowerRisks (PTDC/ECI-CON/29286/2017) and the PhD programs PD/BD/150397/2019 and UI/BD/151150/2021.

Data Availability Statement: The data presented in this study are available on request from the corresponding author.

Acknowledgments: The authors gratefully acknowledge the support of CERIS and Itecons.

Conflicts of Interest: The authors declare no conflict of interest. 


\section{Abbreviations}

List of acronyms used in the article.

\begin{tabular}{|c|c|c|}
\hline Subject & Acronym & Description \\
\hline \multirow{6}{*}{ Cladding material } & $\mathrm{ACF}$ & Architectural concrete façades \\
\hline & CTS & Ceramic tilling system \\
\hline & ETICS & External thermal insulation composite system \\
\hline & NSC & Natural stone cladding \\
\hline & PS & Painted surfaces \\
\hline & $\mathrm{R}$ & Rendered façades \\
\hline \multirow{18}{*}{ Environmental variables } & $\mathrm{Ag}$ & Age \\
\hline & $\mathrm{Ca}$ & Area of the cladding \\
\hline & E & East \\
\hline & Hum & Relative humidity and precipitation \\
\hline & $\mathrm{Ma}$ & Cladding material \\
\hline & $\mathrm{N}$ & North \\
\hline & $\mathrm{NE}$ & Northeast \\
\hline & $\mathrm{Nf}$ & Number of floors above the ground \\
\hline & NW & Northwest \\
\hline & Ori & Orientation \\
\hline & Pol & Pollution from traffic \\
\hline & S & South \\
\hline & SE & Southeast \\
\hline & Sea & Distance to the coastline \\
\hline & SW & Southwest \\
\hline & $\mathrm{S}_{\mathrm{w}}$ & Severity of degradation index \\
\hline & $\mathrm{W}$ & West \\
\hline & Win & Wind \\
\hline \multirow{7}{*}{ Air pollutants } & $\mathrm{CO}$ & Carbon monoxide \\
\hline & $\mathrm{CO}_{2}$ & Carbon dioxide \\
\hline & $\mathrm{NO}_{2}$ & Nitrogen dioxide \\
\hline & $\mathrm{NO}_{\mathrm{x}}$ & Nitrogen oxide \\
\hline & PHAs & Polycyclic aromatic hydrocarbons \\
\hline & $\mathrm{PM}_{10}$ & Particulate matter with aerodynamic diameter below $10 \mu \mathrm{m}$ \\
\hline & $\mathrm{SO}_{2}$ & Sulphur dioxide \\
\hline \multirow{16}{*}{ Statistical analysis } & ANOVA & Analysis of variance \\
\hline & CA & Cluster Analysis \\
\hline & CATPCA & Categorical Principal Components Analysis \\
\hline & $\mathrm{CV}$ & Coefficient of variation \\
\hline & IQR & Interquartile range \\
\hline & Q1 & First quartile-25\% \\
\hline & Q3 & Third quartile-75\% \\
\hline & MLR & Multiple linear regression \\
\hline & PCA & Principal Components Analysis \\
\hline & $\mathrm{r}$ & Pearson correlation coefficient \\
\hline & $\mathrm{R}^{2}$ & Coefficient of determination \\
\hline & SLR & Simple linear regression \\
\hline & $\hat{\gamma}$ & Coefficient of skewness \\
\hline & $\hat{\sigma}$ & Standard deviation \\
\hline & $\hat{k}$ & Kurtosis \\
\hline & $\hat{\mu}$ & Mean \\
\hline
\end{tabular}




\section{Appendix A}

Table A1. Illustrative examples of the claddings' degradation condition, which becomes more severe from condition A to E (discrete scale of $S_{\mathrm{w}}$ ranges, from no visible degradation to generalised degradation).

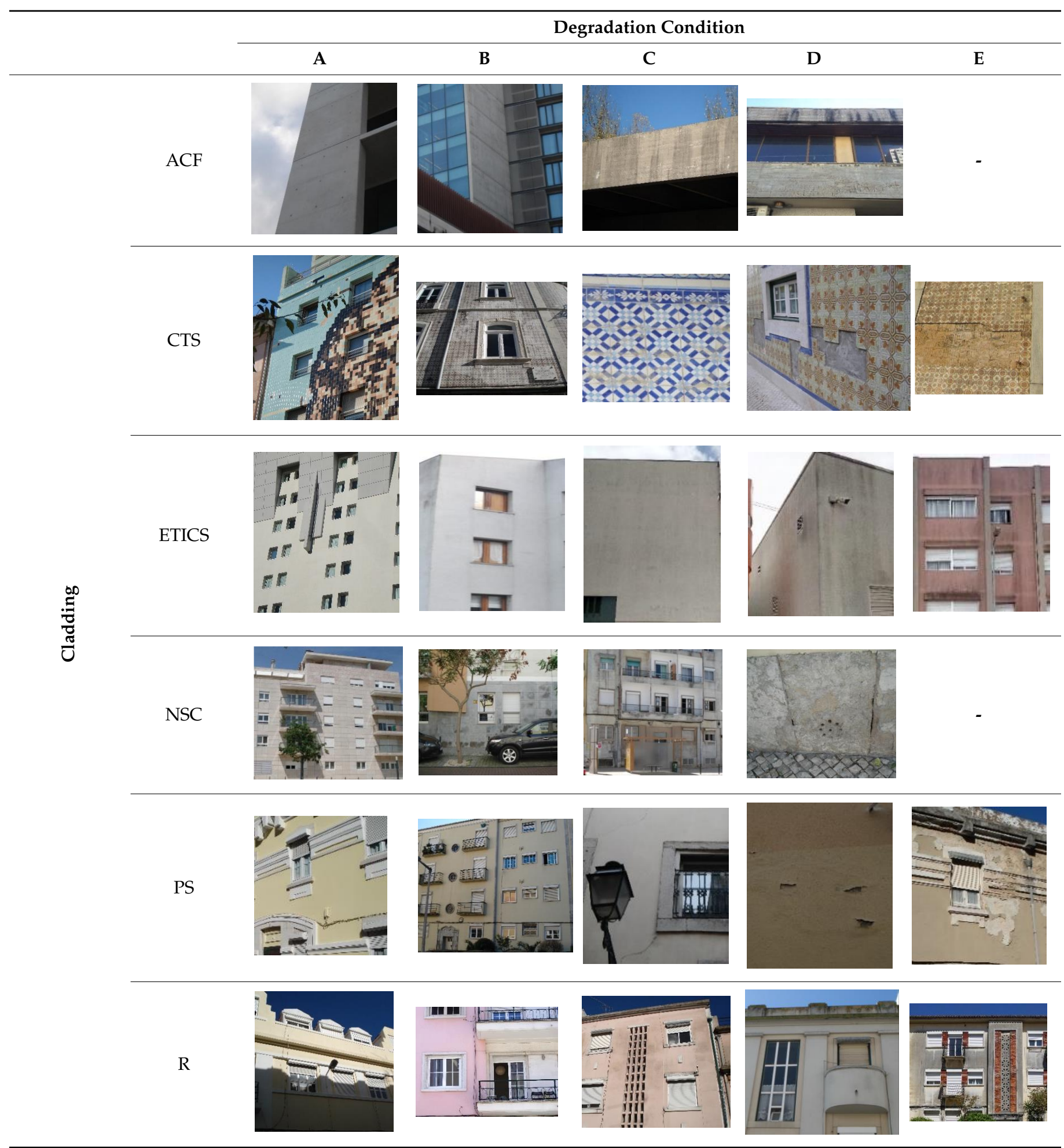




\section{References}

1. Silva, A.; de Brito, J.; Gaspar, P.L. Methodologies for Service Life Prediction of Buildings: With a Focus on Façade Claddings; Springer International Publishing: Zurich, Switzerland, 2016.

2. Phillipson, M.C.; Emmanuel, R.; Baker, P.H. The durability of building materials under a changing climate. Wiley Interdiscip. Rev. Clim. Chang. 2016, 7, 590-599. [CrossRef]

3. Westberg, K.; Norén, J.; Kus, H. On using available environmental data in service life estimations. Build. Res. Inf. 2001, 29, 428-439. [CrossRef]

4. Haagenrud, S.; Krigsvoll, G.; Lisø, K.R.; Thiis, T.; Sjöström, C. Environmental characterisation and mapping with respect to durability. In Proceedings of the 10 DBMC International Conference on Durability of Building Materials and Components, Lyon, France, 17-20 April 2005; Available online: https://www.irbnet.de/daten/iconda/CIB_DC24967.pdf (accessed on 9 November 2021).

5. Ferreira, C.; Barrelas, J.; Silva, A.; de Brito, J.; Dias, I.S.; Flores-Colen, I. Impact of Environmental Exposure Conditions on the Maintenance of Facades' Claddings. Buildings 2021, 11, 138. [CrossRef]

6. Saha, M.; Eckelman, M.J. Urban scale mapping of concrete degradation from projected climate change. Urban Clim. 2014, 9, 101-114. [CrossRef]

7. Lacasse, M.A. Specifying Resistance to Deterioration for Building Elements of Environmental Separation in the NBC. In Technical Report CRBCPI-Y2-R2; National Research Council Canada: Ottawa, ON, Canada, 2018.

8. Sandak, A.; Sandak, J.; Brzezicki, M.; Kutnar, A. Bio-Based Building Skin; Springer Nature: Singapore, 2019.

9. Prieto, A.J.; Macías-Bernal, J.M.; Chávez, M.J.; Alejandre, F.J. Fuzzy modeling of the functional service life of architectural heritage buildings. J. Perform. Constr. Facil. 2017, 31, 04017041. [CrossRef]

10. de Brito, J.; Pereira, C.; Silvestre, J.D.; Flores-Colen, I. Expert Knowledge-Based Inspection Systems-Inspection, Diagnosis and Repair of the Building Envelope; Springer: Cham, Switzerland, 2020.

11. Madureira, S.; Flores-Colen, I.; de Brito, J.; Pereira, C. Maintenance planning of facades in current buildings. Constr. Build. Mater. 2017, 147, 790-802. [CrossRef]

12. Gaspar, P.L. Service Life of Buildings: Methodology for Service Life Prediction of Building Components-Application to External Cement-Renders. Ph.D. Thesis, Universidade Técnica de Lisboa, Lisbon, Portugal, 2009. (In Portuguese)

13. Gaspar, P.L.; de Brito, J. Limit states and service life of cement renders on façades. J. Mater. Civ. Eng. 2011, $23,1396-1404$. [CrossRef]

14. Ximenes, S.; de Brito, J.; Gaspar, P.L.; Silva, A. Modelling the degradation and service life of ETICS in external walls. Mater. Struct. 2015, 48, 2235-2249. [CrossRef]

15. Serralheiro, M.I.; de Brito, J.; Silva, A. Methodology for service life prediction of architectural concrete facades. Constr. Build. Mater. 2017, 133, 261-274. [CrossRef]

16. Tavares, J.; Silva, A.; de Brito, J. Computational models applied to the service life prediction of External Thermal Insulation Composite Systems (ETICS). J. Build. Eng. 2020, 27, 100944. [CrossRef]

17. Silva, A.; de Brito, J. Service life of building envelopes: A critical literature review. J. Build. Eng. 2021, 44, 102646. [CrossRef]

18. Dias, I.S.; Flores-Colen, I.; Silva, A. Critical Analysis about Emerging Technologies for Building's Façade Inspection. Buildings 2021, 11, 53. [CrossRef]

19. Law, D.W.; Holden, L.; Silcock, D. The assessment of crack development in concrete using a terrestrial laser scanner (TLS). Aust. J. Civ. Eng. 2015, 13, 22-31. [CrossRef]

20. Masiero, A.; Costantino, D. TLS for detecting small damages on a building façade. Int. Arch. Photogramm. Remote Sens. Spat. Inf. Sci. 2019, XLII-2/W11, 831-836. [CrossRef]

21. Cole, I.S.; Paterson, D.A.; Lau, D. Holistic Modeling of gas and aerosol deposition and the degradation of cultural objects. In Physical Techniques in the Study of Art, Archaeology and Cultural Heritage; Elsevier: Amsterdam, The Netherlands, 2007; Volume 2, pp. 115-154.

22. Szymczak-Graczyk, A.; Laks, I.; Ksit, B.; Ratajczak, M. Analysis of the impact of omitted accidental actions and the method of land use on the number of construction disasters (a case study of Poland). Sustainability 2021, 13, 618. [CrossRef]

23. Grøntoft, T. Conservation-restoration costs for limestone façades due to air pollution in Krakow, Poland, meeting European target values and expected climate change. Sustain. Cities Soc. 2017, 29, 169-177. [CrossRef]

24. Kus, H.; Nygren, K.; Norberg, P. In-use performance assessment of rendered autoclaved aerated concrete walls by long-term moisture monitoring. Build. Environ. 2004, 39, 677-687. [CrossRef]

25. Corvo, F.; Reyes, J.; Valdes, C.; Villaseñor, F.; Cuesta, O.; Aguilar, D.; Quintana, P. Influence of air pollution and humidity on limestone materials degradation in historical buildings located in cities under tropical coastal climates. Waterairand Soil Pollut. 2010, 205, 359-375. [CrossRef]

26. Daniotti, B.; Paolini, R.; Cecconi, F.R. Effects of ageing and moisture on thermal performance of ETICS cladding. In Durability of Building Materials and Components; Springer: Berlin, Germany, 2013; Volume 3, pp. 127-171.

27. Bauer, E.; Souza, J.S.; Mota, L.M.G. Degradation of rendered facades in the buildings of Brasília, Brazil. Ambiente Construído 2021, 21, 23-43. (In Portuguese) [CrossRef]

28. Auras, M.; Bundschuh, P.; Eichhorn, J.; Kirchner, D.; Mach, M.; Seewald, B.; Snethlage, R. Salt deposition and soiling of stone facades by traffic-induced immissions. Environ. Earth Sci. 2018, 77, 1-16. [CrossRef] 
29. Pires, R.; de Brito, J.; Amaro, B. Statistical survey of the inspection, diagnosis and repair of painted rendered façades. Struct. Infrastruct. Eng. 2014, 11, 605-618. [CrossRef]

30. Crocker, C.R. Influence of orientation on exterior cladding. In Canadian Building Digests; National Research Council Canada: Ottawa, ON, Canada, 1970; pp. 101-150.

31. Amaro, B.; Saraiva, D.; de Brito, J.; Flores-Colen, I. Statistical survey of the pathology, diagnosis and rehabilitation of ETICS in walls. J. Civ. Eng. Manag. 2014, 20, 511-526. [CrossRef]

32. Pereira, C.; de Brito, J.; Silvestre, J.D. Contribution of humidity to the degradation of façade claddings in current buildings. Eng. Fail. Anal. 2018, 90, 103-115. [CrossRef]

33. Chai, C.; de Brito, J.; Gaspar, P.L.; Silva, A. Predicting the service life of exterior wall painting: Techno-economic analysis of alternative maintenance strategies. J. Constr. Eng. Manag. 2014, 140, 04013057. [CrossRef]

34. Silva, A.; Gaspar, P.L.; de Brito, J.; Neves, L.C. Probabilistic analysis of degradation of façade claddings using Markov chain models. Mater. Struct. 2016, 49, 2871-2892. [CrossRef]

35. Pires, V.; Amaral, P.M.; Simão, J.A.R. Experimental procedure for studying the degradation and alteration of limestone slabs applied on exterior cladding. Res. Sq. 2021, 1-21. [CrossRef]

36. Urosevic, M.; Sebastián-Pardo, E.; Cardell, C. Rough and polished travertine building stone decay evaluated by a marine aerosol ageing test. Constr. Build. Mater. 2010, 24, 1438-1448. [CrossRef]

37. Ferreira, C.; Canhoto Neves, L.; Silva, A.; de Brito, J. Stochastic Petri-net models to predict the degradation of ceramic claddings. Build. Res. Inf. 2019, 47, 697-715. [CrossRef]

38. Köliö, A.; Pakkala, T.A.; Lahdensivu, J.; Kiviste, M. Durability demands related to carbonation induced corrosion for Finnish concrete buildings in changing climate. Eng. Struct. 2014, 62, 42-52. [CrossRef]

39. Grøntoft, T. Estimation of damage cost to building façades per kilo emission of air pollution in Norway. Atmosphere 2020, 11, 686. [CrossRef]

40. Watt, J.; Tidblad, J.; Kucera, V.; Hamilton, R. The Effects of Air Pollution on Cultural Heritage; Springer: Berlin, Germany, 2009.

41. Slezakova, K.; Castro, D.; Begonha, A.; Delerue-Matos, C.; da Conceição Alvim-Ferraz, M.; Morais, S.; do Carmo Pereira, M. Air pollution from traffic emissions in Oporto, Portugal: Health and environmental implications. Microchem. J. 2011, 99, 51-59. [CrossRef]

42. Brimblecombe, P. The effects of air pollution on the built environment. In Air Pollution Reviews_-Volume 2; Imperial College Press: London, UK, 2003.

43. Sousa, V.; Almeida, N.; Meireles, I.; de Brito, J. Anomalies in wall renders: Overview of the main causes of degradation. Int. J. Archit. Herit. 2011, 5, 198-218. [CrossRef] 